ÉGYPTE

monde arabe

\section{Égypte/Monde arabe}

25 | 1996

Anthropologies de l'Égypte 2

\title{
La voix du poète : tarab et poésie dans le chant mystique soufi
}

\section{Michael Frishkopf}

\section{(2) OpenEdition}

\section{Journals}

Édition électronique

URL : https://journals.openedition.org/ema/841

DOI : 10.4000/ema.841

ISSN : 2090-7273

\section{Éditeur}

CEDEJ - Centre d'études et de documentation économiques juridiques et sociales

\section{Édition imprimée}

Date de publication : 30 mars 1996

Pagination : 85-119

ISSN : 1110-5097

\section{Référence électronique}

Michael Frishkopf, «La voix du poète : tarab et poésie dans le chant mystique soufi », Égypte/Monde arabe [En ligne], 25 | 1996, mis en ligne le 08 juillet 2008, consulté le 07 juillet 2022. URL : http:// journals.openedition.org/ema/841 ; DOI : https://doi.org/10.4000/ema.841

Ce document a été généré automatiquement le 7 juillet 2022.

Tous droits réservés 


\title{
La voix du poète : tarab et poésie dans le chant mystique soufi
}

\author{
Michael Frishkopf
}

\section{NOTE DE L'ÉDITEUR}

Traduit de l'anglais par Baudouin Dupret.

1 II n'y a pas véritablement de traduction du concept esthétique de tarab ${ }^{1}$. Au sens strict, cela renvoie à une émotion musicale et aux ressources traditionnelles de la poésie musicale permettant de la susciter. Il s'agit, en particulier, du chant expressif en solo d'une poésie évocatrice dans un style improvisé utilisant le système traditionnel du maqâm (mode mélodique). Poésie affective, intonation et énonciation précises, juste élaboration du maqâm, improvisation, modulation, exécution correcte de la qafla (cadence mélodique) sont autant de facteurs essentiels à l'exécution du tarab².

2 Le tarab dépend également des interactions exécutant-auditeur dans lesquelles les auditeurs réagissent à la musique en exprimant leur émotion par des exclamations et des gestes, en particulier au moment de la pause qui suit la qafla; en retour, le chanteur est mis en mouvement et dirigé par ce feedback ${ }^{3}$. L'émotion est partagée par les participants, échangée et amplifiée à travers cette relation dynamique. La relation harmonieuse du chanteur et des paroles qu'il interprète revêt également une importance majeure dans le tarab, du fait que le chanteur doit se, produire avec sincérité (sidq) et ainsi exprimer un sentiment vrai permettant de communiquer une émotion aux auditeurs.

De manière plus abstraite, les Égyptiens donnent du tarab les descriptions suivantes: une relation d'harmonie (insigâm) ou d'équilibre '(mu'âdala) entre exécutant et auditeur; un échange de sentiments (tabâdul al-shu'ûr) qui, entre ces derniers, peut atteindre une véritable unité (wahdat al-shu'ur); la fusion (dhawb) affective de deux en un; la coexistence (mu'âyasha] harmonieuse d'un exécutant et d'un auditeur, ou d'un 
poème et d'un exécutant; ou encore, la relation (irtibât d'une personne à quelque chose de beau, toute beauté comportant un aspect émotionnel.

D'un point de vue technique, seul le chanteur de tarab devrait être appelé mutrib (pi. mutribîn], même si ce terme a fini par simplement signifier « chanteur » (mughanni). Il y a nombre de mutribîn au Caire, mais pour beaucoup d'Égyptiens, le tarab s'est raréfié en tant que musique séculière après la disparition des grands chanteurs de tarab non religieux comme Umm Kulthûm. Ceci étant, maints auteurs considèrent que l'inshâd soufi - la musique mystique qui fait l'objet de cet article - est riche en tarab ${ }^{4}$. Elle rappelle en effet, par ses caractéristiques musicales et sa dynamique, l'ancienne tradition du tarab, et par son impact émotionnel, elle est beaucoup plus puissante que d'autres formes de musique égyptienne contemporaine.

Pourquoi la musique soufie serait-elle si chargée en tarab? La réponse est en partie historique: la musique religieuse, conservatrice en elle-même, a gardé certaines des caractéristiques de la musique arabe qui, auparavant, dominaient également la musique profane, mais qui ont progressivement disparu pour des raisons liées aux changements politiques, sociaux et économiques modernes. Cependant, les facteurs historiques ne peuvent à eux seuls expliquer pourquoi la musique soufie a beaucoup évolué ces dernières années, quoique insuffisamment pour déloger le tarab. Il vaudrait mieux chercher l'explication dans le système soufi de croyances, pratiques, affects et éléments esthétiques qui facilite les relations - dont dépend le tarab - d'harmonie et l'échange de sentiments entre poète, chanteur et auditeurs.

De plus, la réalisation de l'inshâd soufi en dehors du cadre des confréries requiert un haut degré de communication émotionnelle, cette musique étant amenée à jouer un rôle crucial dans l'établissement d'une solidarité affective de groupes sociaux éphémères ainsi que, généralement, dans la construction d'un affect au sein de ce qu'il est convenu d'appeler le soufisme populaire (que j'appellerai ici le soufisme « informe! »). Le tarab n'est donc pas seulement mis en œuvre par le soufisme, il en est aussi l'exigence. Les facteurs qui le favorisent sont aujourd'hui absents de la musique arabe profane, qui a connu une série de transformations résultant des influences et intérêts occidentaux, de modifications démographiques, de l'impact de la technologie, de la transformation des goûts populaires, etc.

7 Dans cet article, je me pencherai sur le rôle du poète soufi ${ }^{5}$, sur le pouvoir affectif de sa poésie et sur sa relation au munshid (chanteur soufi) et à l'auditeur quand il crée du tarab. C'est, selon moi, le domaine commun de la pensée, du sentiment et de la pratique soufis qui permet au poète de communiquer une émotion mystique intense, par le biais du langage, à un munshid qui perçoit les paroles du poète de manière suffisamment forte pour faire l'expérience de l'état affectif qui l'a engendré. Harmonie et échange de sentiments constituent précisément cette "conformité émotionnelle ", si bien que le munshid reçoit le tarab du poète (yatrab mi nal-shấir). Puis ce domaine commun permet le développement d'une "conformité émotionnelle " entre chanteur et auditeur, de sorte que l'auditeur reçoit le tarab du chanteur [yatrab min al-munshid) et donc, par voie transitive, la reçoit de ce fait du poète. Dans la musique profane, le niveau d'émotion est plus faible et les connexions émotionnelles reliant le poète, le chanteur et l'auditeur le sont aussi : il n'y a pas de terrain commun qui, en profondeur et en ampleur, soit comparable au soufisme pour ce qui est de susciter de l'émotion et de faciliter l'échange émotionnel. 
8 Je développerai ce point dans les pages qui suivent. En premier, lieu, je présenterai un tableau ethnographique du soufisme et de l'inshâd soufi dans l'Égypte contemporaine. Puis je m'attacherai plus longuement au poète soufi, à son statut dans le soufisme et à la nature du processus créatif pour tenter de comprendre la raison de la charge affective de ses paroles en dépit de l'opacité fréquente de leur contenu assertif. J'aborderai ensuite la question du statut du munshid professionnel et de sa connexion spirituelle aux paroles qu'il chante et au poète soufi qui les a écrites. Enfin, je me pencherai sur le rôle de la poésie dans la construction même du tarab.

9 Tout au long de cette étude, je m'inspirerai de bribes de discours soufis locaux et de mes propres hypothèses. Au détour de ces questions touchant à l'émotion musicale réside également un problème épistémologique : quelle relation y a-t-il entre la théorie de l'outsider (ma réflexion sur la musique, la mystique et l'émotion) et le discours de l'insider (en l'espèce, un corpus informellement articulé et constitué au départ par les nombreuses personnes intéressées par le soufisme ou participant à des séances d'inshâd, ce qui ne peut qu'approximativement être appelé «théorie » et qui combine des idées mystiques et esthétiques). J'ai mes hypothèses et mes collègues soufis égyptiens ont les leurs.

10 Toutefois, je ne considère pas cette situation comme le reflet de la distinction habituelle qui met l'accent sur le caractère incommensurable des positions de l'insider et de l'outsider, ce dernier ayant le privilège d'une expression plus objective de la réalité. Je ne considère pas non plus que mes théories constituent des « extraits du discours local », fondées empiriquement sur des données empiriques, à l'instar du physicien qui construirait une théorie correspondant à ce qu'il a expérimenté. Je considère au contraire que théorie et discours sont interdépendants, qu'ils constituent le produit de différents types de pensée qui sont en relation et dans lesquels les spéculations d'un outsider faiblement acculturé, se référant à différents paradigmes abstraits, sont informées par le discours de l'insider. Après deux années de terrain, passées à vivre et à parler avec des soufis, mes réflexions ont été naturellement imprégnées des leurs : je pense « avec » et « dans », je ne peux pas penser « en dehors ». Mon propre raisonnement est toujours en dialogue avec le discours soufi (parfois intérieurement, parfois dans des conversations) et de ce fait, il y appartient dans un certain sens.

11 Cet article se veut une extension théorique de la pensée et du discours soufis en Égypte. Tantôt mon rôle se limite à passer au crible et à codifier ce que j'ai observé et expérimenté en "remplissant des vides", en triant les idées, en allégeant les contradictions et en tirant des conséquences logiquement proches. Tantôt je m'engage plus loin dans le domaine spéculatif en confrontant mes idées à celles des soufis rencontrés au cours de l'enquête. Il n'y a pas de métalangage. Mes théories ne remettent en aucun cas le discours local en question, pas plus qu'elles ne laissent entrevoir de « vraie réalité » qui dépasserait l'entendement des soufis égyptiens pour se révéler miraculeusement au chercheur. De la même façon, le discours de l'insider ne contredit pas mes théories : il ne laisse que des blancs, du fait de ce qu'il ne dit pas ou du fait d'implications qui font partie de l'impensé. Mes théories pourraient donc être mieux décrites comme une espèce de philosophie spéculative de l'expérience locale, qui aurait tout aussi bien pu être écrite - quoique fort différemment - par des Égyptiens ayant goût et penchant pour pareil projet.

Le soufisme égyptien contemporain 
12 À première vue, les processus d'émotion expressive dans l'exécution de l'inshâd soufi peuvent paraître similaires à ceux d'autres modes (populaires) de chanter. Il est vrai que musique soufie et musique profane partagent, en Égypte rurale comme en Égypte urbaine, de nombreux éléments. L'inshâd soufi se distingue cependant du chant profane par le fait que sa musique, sa poésie, ses exécutants, le contexte et les auditeurs sont nourris par le monde riche et diversifié de la pratique, du langage, de la pensée et de la théorie soufis, toutes choses formant un fond commun et constituant autant de voies potentielles à une émotion expressive qui ne saurait être suscitée par le seul partage des mêmes références ou valeurs culturelles, sociales ou régionales.

L'islam orthodoxe est fondé sur la sharî'a, la loi sacrée dérivée de la révélation coranique et de la Sunna (dires et faits du prophète Muhammad). Par le langage, la sharî'a décrit l'ordre du cosmos, détermine les articles de foi et régule le comportement, fournissant ainsi des modèles normatifs pour la vie sociale. Ceci dit, une formulation purement légaliste de l'islam, dans lequel le Verbe de la Révélation assure la médiation entre les deux rives du fossé infini séparant le Dieu transcendant et la création, laisserait un vide émotionnel. Ce vide est rempli par le soufisme, qui vise un type d'expérience religieuse supra-rationnel, mettant l'accent sur l'amour divin (al-hubb alillâhi) et sur la puissance du monde des esprits ('alam al-arwâh], particulièrement les prophètes et les saints qui sont objet d'amour et de dévotion, source de bénédiction (baraka) et d'intercession. Pour nombre de soufis, si la sharîa est nécessaire à la régulation de la société, le soufisme (al-tasawwuf) constitue l'essence (ghawar) de l'islam. La sharî'a fait appel à l'intellect ('aql), lequel est insuffisant pour comprendre la Vérité mystique (al-haqîaa). La perception spirituelle (basîra ou shafafiyya) est plutôt située au niveau du cœur (qalb). L'intellect, bien qu'intelligent, est voilé (mahjûb) et reste confiné au visible, au matériel, au logique, alors que le cœur transcende ces limites pour en arriver à percevoir des vérités plus élevées constituées de sentiment (ihsâs). Le soufisme privilégie le cœur par rapport à l'intellect et, de la sorte, l'intuition affective par rapport à la perception discursive. Comme en Occident, le cœur est également le locus de l'amour (hubb).

14 Aujourd'hui, en Égypte ${ }^{6}$, le soufisme est communément décrit comme Livre (kitâb, le Coran), Sunna et amour (hubb). D'une manière ou d'une autre, l'amour, c'est-à-dire la capacité d'un esprit (rûh) à se joindre de manière désintéressée à un autre, forme la base de la quasi-totalité du discours et de la pratique soufis. Le parcours de cet amour est jalonné de désirs (shahawât) enracinés dans le soi (nafs: le ruh lumineux et le nafs terrestre sont les deux éléments antagoniques de la psychologie soufie). Du point de vue soufi, l'amour pur ne peut viser que Dieu seul et ne peut avoir de visée égoïste. Le soufi tend à la purification du soi, siège du désir, pour élever l'esprit à l'amour pur et à Dieu. Pareille purification peut être représentée métaphoriquement comme de l'ascétisme, c'est-à-dire la purification du corps et du soi, bien que les véritables pratiques ascétiques soient rares aujourd'hui.

15 L'amour soufi comporte différents types et degrés, y compris l'amour platonique des compagnons en soufisme et du shaykh ; l'amour spirituel des saints (wâli, pl. awliyà), des prophètes (nabi, pi. anbiyâ') - particulièrement du Prophète Muhammad - et des " gens de la maison " (ahl al-bayt, les descendants immédiats du Prophète par son beau-fils 'Ali) ; l'amour divin (al-hubb al-ilâhi). La joie de l'amour, décrit comme affection (widad) ou amour (mahabba, hubb, sababa), intensifié en amour extatique, en passion (hiyam, 'ishq, walah, wajd), est souvent entremêlée de la souffrance du désir ardent, qui provient 
de l'absence de réponse de l'aimé (mahbûb): les mots shawq (désir passionnel), law'a (mal d'amour), huzn, kadar, shajan, shajw et asan (anxiété, douleur) sont utilisés; le corps de l'amant peut devenir faible, émacié (saqîm), malade (symbolique de la destruction du nafs et de l'effet d'une passion non satisfaite) ; la source de tous ces états demeure l'amour et le désir d'union avec l'aimé, jusqu'au sacrifice de soi.

Dans les degrés les plus extrêmes de l'amour ('ishq ou wajd), l'amant perd ses attributs individuels et est assimilé à l'aimé, un état connu techniquement sous le nom de fana' (annihilation). Un soufi peut rechercher le fana' dans son shaykh ou dans le Prophète, mais la plus haute forme de fana' est en Dieu, Sur un plan moins élevé, l'amour soufi se manifeste comme générosité désintéressée, tolérance, compassion, empathie pour les autres, quelle que soit leur affiliation religieuse. La quasi-totalité de la poésie soufie parie d'amour, de désir ardent, ou vante l'aimé. Le soufi est souvent appelé muhibb (pl. muhibbîn) ou 'âshiq (pl. 'âshiqîn) ; les deux mots signifient " amant ». Comme me le dira un poète soufi : « II est une tradition qui considère que votre foi est incomplète si vous n'aimez pas Dieu et le Prophète plus que vous-même. Cet amour est également un thème majeur pour les soufis. Vous devez vous souvenir de ceux que vous aimez. Dieu nous a donné par amour ; nous devons Lui renvoyer l'amour, nous y extasier... Le soufi aime jusqu'à s'oublier lui-même. »

Sous-jacente à la théorie et à la pratique de l'amour soufi, il y a la notion de proximité spirituelle. La cosmologie soufie est centrée sur le monde des esprits ('alam al-arwâh), lequel n'est pas déterminé par les limites du monde physique et, de ce fait, autorise l'établissement de relations émotionnelles avec d'autres sans égard à leur existence dans le monde physique du temps et de l'espace ${ }^{7}$. Le monde de l'esprit existait dans la pré-éternité (a/-'âlam al-azali), avant la Création. En ce temps, les esprits se rencontraient et certains établissaient entre eux des relations étroites; le rapport spirituel que deux personnes peuvent ressentir sur terre résulte de leur relation spirituelle antérieure. On a souvent dit qu'après la mort du corps, les esprits s'en vont vers l'isthme (barzakh) où la plupart attendront le Jour du Jugement. Mais les esprits vertueux (sâlihîn), dont font partie les awliyâ', sont libres d'aller et venir où ils veulent. Ils peuvent, de la sorte, rencontrer le vivant, souvent dans les rêves, et sont présents dans leurs sanctuaires, particulièrement à l'occasion de célébrations spéciales comme les mouleds (mawlid, pl. mawâlid, fête commémorative d'un saint).

Pour le soufi, Dieu n'est pas infiniment loin, mais plutôt infiniment près; l'on se rapproche de Lui en fonction de son degré de développement spirituel. C'est toutefois avant tout pour la proximité de son shaykb et des awliyấ' que le soufi lutte. Le mot utilisé pour dire « saint » (wâli) signifie en effet « proche » ou « ami ». Le Prophète, ses descendants et les saints sont aimés de Dieu et, par voie de conséquence, proches de Lui. Le wâli soufi est une personne qui, par la vertu de son talent spirituel et de son effort mystique, s'est rapprochée de Dieu, a reçu de l'Aimé une illumination mystique et une bénédiction (baraka). Les awliyấ' et les anbiyâ' (prophètes), particulièrement le Prophète Muhammad et ses descendants sont donc l'objet, dans le soufisme égyptien,d'un grand amour spirituel, de respect et de dévotion'.

Bien qu'il n'y ait pas de procédure officielle de canonisation en islam, les miracles (karamât) réalisés par le wâli au cours de sa vie sont des indices de la position mystique qu'on lui prête, dans la mesure où les miracles sont des dons offerts à celui qui cherche Dieu sincèrement. Les soufis rapportent constamment les récits de ces miracles, renforçant ainsi la réputation du saint qui les a réalisés, la majesté de Dieu qui l'a 
pourvu de tels dons et les limites de l'intellect qui ne peut les comprendre (ce qui induit implicitement la supériorité sur ce dernier du cœur et de l'âme). Aimer quelqu'un, c'est aussi vanter ses qualités et demander pour lui la bénédiction de Dieu. C'est pourquoi le soufisme est si riche en poèmes laudatifs (madih ou madh) qui honorent essentiellement le Prophète.

Dans la mesure où la proximité spirituelle de Dieu est possible, il est normal de demander intercession (shafâ'a) ou assistance (madad) de quelqu'un qui est plus proche de Dieu qu'on ne l'est soi-même, en particulier les awliyâ' qui disposent de Sa bénédiction (baraka). Les relations qui unissent au saint sont également, bien qu'enracinées dans l'amour, caractérisées par la « pétition » (tawassul), surtout dans le sanctuaire (maqam) du wâli où sa présence spirituelle est ressentie comme plus forte 9 . Les sanctuaires de saints importants sont toujours fréquentés, mais le rythme des visites s'intensifie les jours de fêtes, surtout à l'époque du mouled annuel. Les visiteurs récitent la fatiha (la sourate introductive du Coran) devant la grille entourant le sanctuaire et forment des vœux pour obtenir l'intercession et la baraka du saint ${ }^{10}$. Ce système de vénération est lié au respect manifesté au shaykh vivant d'un ordre soufi du fait que, lorsqu'un shaykh meurt, sa tombe devient un sanctuaire et un lieu d'actes dévotionnels et supplicatoires. Au bout de quelques années, il peut commencer à être considéré comme un saint, et un mouled annuel sera tenu en son honneur.

21 Le parcours conduisant au double but de purifier l'esprit et d'élever l'âme est accompli formellement à l'intérieur de la confrérie (tarîqa, pl. turuq, littéralement: le « chemin »), qui est l'unité sociale, pratique et doctrinale du soufisme conduite par un shaykh. Un musulman souhaitant adhérer prononce un serment particulier ('ahd) devant le shaykh ou devant son délégué, à la suite de quoi il devient un disciple (murîd, pl; murîdin). Les membres de la confrérie sont désignés collectivement comme "amants" (habîb, pl. ahbâb ou muhibbin) et le thème de l'amour fraternel entre membres de la confrérie est mis en avant. Certains ordres soufis utilisent des salutations particulières, comme le baiser des mains, pour manifester l'affection et le respect entre les membres. Le plus haut degré d'amour et de vénération est manifesté au shaykh du fait de son savoir, de sa piété, de sa distinction et de sa position spirituelle élevée. Le shaykh n'est pas seulement considéré comme un enseignant et un guide spirituel, mais aussi comme une source de bénédiction (baraka) héritée de son propre shaykh.

Les shaykh du soufisme forment une unique généalogie spirituelle dans la mesure où chacun a lui-même un shaykh; ses antécédents spirituels constituent une chaîne remontant éventuellement au Prophète par l'intermédiaire de son beau-fils, le calife 'Ali. Tous les grands soufis et saints et, plus généralement, tous les soufis sont liés à une famille spirituelle. Cependant, les premiers enseignants soufis n'ont pas établi de confréries formelles. Ce n'est qu'au XII siècle que les filières majeures de confrérie ont commencé à constituer des organisations sociales, dont plusieurs existent encore aujourd'hui.

En Égypte, les soufis relient les principales confréries aux «quatre pôles » ou arba'a aqtâb $b^{11}$ : Sayyid 'Abd al-Qâdir al-jilâni (fondateur de la confrérie Qâdiriyya), Sayyid Ahmad al-Badawi (confrérie Ahmadiyya), Sayyid Ibrâhîm al-Disûqi (confrérie Burhamiyya) et Sayyid Ahmad al-Rifâ'i (confrérie Rifa'iyya), À ces noms, on ajoute souvent celui de Sayyid Abu-l-Hasan al-Shâdhili (confrérie Shâdhiliyya). Ces fondateurs sont considérés comme les awliya' du rang le plus haut, donc comme une source 
abondante de baraka qui leur provient de Dieu par le Prophète et ses descendants. Cette baraka passe par leurs disciples et la chaîne généalogique s'étend jusqu'aux shaykh d'aujourd'hui.

Selon la plupart des soufis, les confréries sont des chemins différents menant au même but, tout comme les rayons d'une roue se rattachent tous au moyeu. Toutes les voies du soufisme mettent l'accent sur la purification de l'esprit et l'élévation de l'âme pour se rapprocher de l'Aimé; elles insistent sur l'accomplissement des devoirs religieux de base (par exemple la prière quotidienne) prescrits par la shari' $a$, en même temps que sur l'affinement de la parole et de l'agir. Être poli (mu'addab), moral (akhlâqi), véridique (sadîq), sincère (khâlis), respectueux (muhtarim) sont les exigences de base que le murîd doit remplir et sans lesquelles il ne peut y avoir de progrès spirituel.

Les confréries se distinguent par leur enseignement et la forme de leurs pratiques rituelles. Chacune a son corpus de prières et de poèmes. Les recueils de poésie (qasîda, pl. qasấ'id) regroupent souvent des poèmes écrits ou sélectionnés par le fondateur de la confrérie ou par un shaykh qui est l'un de ses descendants spirituels. Les poèmes sont souvent écrits en l'honneur du Prophète ou d'une autre figure spirituelle, ils font une déclaration d'amour ou demandent une intercession spirituelle. D'autres poèmes expriment les sentiments mystiques et les doctrines du shaykh. Ce genre de poésie est enraciné dans l'expérience émotionnelle du soufisme lui-même.

Sous la tutelle de son shaykh, le disciple progresse. Tout au long du chemin, Dieu peut gratifier celui qui est en quête d'ahwâl (sg. hâl), c'est-à-dire d'états éphémères d'inspiration mystique ou d'extase émotionnelle. Le shaykh impose à chaque disciple des prières surérogatoires qui doivent être répétées un nombre de fois déterminé sur le chapelet, habituellement après la prière normale. Le disciple veille à sa moralité et à son comportement, exécute les actes rituels requis et participe aux activités de la confrérie. Il peut être requis pour servir le shaykh dans ses activités sociales ou quotidiennes; de son côté, le shaykh veille à sa progression spirituelle et lui impose les exercices qui semblent lui convenir. La plupart des confréries organisent une ou deux réunions hebdomadaires, soit dans une mosquée soit dans un autre lieu de rencontre. La rencontre peut comprendre des récitations coraniques, des sessions d'enseignement, d'inshâd de dhikr.

Le terme de dhikr couvre un certain nombre de pratiques, individuelles ou collectives, à travers lesquelles les participants se concentrent sur Dieu, Le principal rituel collectif soufi est la mention des noms de Dieu (dhikr al-asma' al-husna). Dans cette cérémonie, les disciples se rapprochent de Dieu en chantant ensemble et en rythme Ses noms et, souvent, en exécutant des mouvements corporels rythmés (tafqîr). Parallèlement, les chanteurs peuvent se livrer à l'inshâd, parfois accompagné d'instruments de musique. À chaque moment du dhikr, il y a franchissement progressif d'un niveau de chant, de mouvement, de musique et d'émotion. En Égypte, aujourd'hui, on pratique le dhikr aussi bien à l'intérieur qu'à l'extérieur des confréries.

Lors des réunions, le dhikr peut comprendre de l'inshâd, mais il est rarement fait usage d'instruments - jamais, en tout cas, à l'intérieur d'une mosquée. L'extériorisation de l'émotion est restreinte et la transe généralement interdite. En revanche, quand le dhikr est accompli à l'extérieur des confréries, à l'occasion de mariages ou d'autres manifestations de la vie sociale, ou encore à l'occasion de mouleds, les restrictions sociales et doctrinales de la confrérie et de son shaykh sont absentes. Dans pareil contexte, l'utilisation d'instruments de musique est quasi générale, il y a davantage de 
spontanéité et moins de formalisme dans l'accomplissement de la performance et les participants adoptent une gamme beaucoup plus large de comportements émotionnels.

Le soufisme est souvent assimilé aux confréries elles-mêmes. C'est une erreur dans la mesure où, en Égypte, la participation aux confréries est relativement limitée alors que les traits caractéristiques de la pensée, de la croyance et de la pratique soufies s'étendent au-delà des limites formelles des confréries et touchent, d'une façon ou d'une autre, une grande partie de la société musulmane. Ce que j'appelle «soufisme informel » est un système plus large de pensée, de sentiment et d'action qui englobe les confréries en tant qu'elles constituent des structures sociales cristallisées d'une manière spécifique, mais qui s'étend de manière informe au-delà d'elles, bien que ce soit sans autorité centrale, ordre hiérarchique, doctrine explicite ou formes rituelles établies. Certains ont pu appeler ce système, de manière quelque peu péjorative, « religion populaire ». Il reste qu'on y retrouve la même vision soufie de l'univers que celle des confréries. La différence majeure entre les types formel et informel réside dans l'absence, chez ce dernier, des structures sociales et des disciplines spirituelles qui caractérisent les confréries. En fait, de nombreux "soufis informels» sont officiellement membres de confréries et ont prêté serment à un shaykh mais, pour différentes raisons, ils n'assistent pas régulièrement aux séances. Dans le langage usuel, ils sont souvent appelés muhibbîn ou 'âshiqîn.

Le soufisme informel est centré sur la vénération, l'amour, les bénédictions et l'intercession du Prophète, des ahl al-bayt et des awliyâ'. Alors que la réunion régulière et structurée des confréries est le point de convergence des pratiques collectives, ce sont les centaines de mouleds annuels - véritables festivals religieux ressemblant à des carnavals et jalonnant irrégulièrement, sur une période d'une nuit à deux semaines, le calendrier - qui constituent les occasions sociales majeures du soufisme informel ${ }^{12}$. Chaque mouled s'organise spirituellement et spatialement autour du sanctuaire d'un saint particulier ${ }^{13}$.

Les mouleds rassemblent les ordres soufis qui font leurs propres dhikr/prières, et d'autres muhibbîn qui viennent saluer le saint, baigner dans le rayonnement de sa baraka et rencontrer d'autres ahbâb. Les soufis plus aisés peuvent établir une khidma (un lieu temporaire où boisson et nourriture sont servis sans contrepartie au tout venant) qui sert de point de ralliement pour des rassemblements formels ou informels; ils peuvent également apporter leur soutien à un munshid pour qu'il chante à l'occasion de grandes séances informelles de dhikr auxquelles tout le monde peut se joindre. On pourvoit généreusement aux besoins des mendiants soufis et des magâzib (soufis qui, de naissance ou en raison de leurs pratiques mystiques excessives, ont perdu leurs facultés mentales). Le mouled draine souvent des colonnes de spectateurs non soufis qui viennent simplement profiter de l'atmosphère festive ; il n'y a pas de restriction sur la nature de l'assistance. Le mouled est ouvert, créatif, improvisé, parfois même chaotique, à l'inverse de l'ordre rituel fermé de la réunion de confrérie. C'est l'occasion de faire montre d'altruisme et de manifester la nature de l'amour soufi. À plus petite échelle, les layâli dîniyya (sg. layla; littéralement: nuit religieuse), qui ne durent qu'une soirée, et la célébration de différents moments sociaux, accompagnée d'inshâd et de dhikr, se déroulent dans la même atmosphère.

À travers le soufisme, formel ou non, les participants sont unis par un sentiment partagé d'amour, à la fois pour le prochain et pour des objets spirituels, fondé sur une vision du monde et une expérience communes. Dans la confrérie, l'unité émotionnelle 
est le résultat de l'initiation, d'une allégeance commune au shaykh, d'une longue familiarité des membres, de croyances et d'enseignements communs propres à la confrérie et de pratiques dévotionnelles régulières, ainsi que de l'accomplissement du dhikr collectif. Le dhikr n'est ici qu'un facteur parmi d'autres, qui traduit l'unité au moins autant qu'il la construit. Les soufis informels assistant à une layla ou à un mouled sont liés semblablement par l'amour. L'absence de séances rituelles établies, de rencontres régulières et de limites définies signifie que l'unité émotionnelle du dhikr du soufisme informel est plus éphémère et repose largement sur la performance ellemême. La force émotionnelle d'un tel rituel suffit à forger une sorte d'ordre affectif collectif, au moins le temps du mouled, bien que cet ordre ne se manifeste jamais comme une structure sociale ou un forme rituelle rigide ; il s'agit bien davantage d'une expérience émotionnelle et mystique partagée. Durant le mouled ou la layla, la musique soufie assume une responsabilité beaucoup plus importante dans la construction de cette unité émotionnelle que dans la réunion de confrérie. Aussi le tarab est-il requis de manière plus impérative dans les séances de dhikr du soufisme informel.

L'inshâd soufi

Bien que boudée par l'islam orthodoxe, la musique est largement acceptée, aussi bien en théorie qu'en pratique, au sein des courants mystiques et dévotionnels de l'islam connus globalement sous le nom de soufisme. Les émotions tirées de l'organisation du son avec le mouvement, la respiration et le chant - notamment à travers le dhikr - ont été longtemps utilisées pour produire un sentiment mystique dans les rassemblements soufis.

En Égypte, on fait généralement référence à la musique soufie en parlant d'inshâd, encore d'inshâd al-sûfi ${ }^{14}$. J'utilise ici le terme de « musique » au sens de "son destiné à la contemplation perceptive». J'ajouterai que ce terme occupe un champ sémantique différent de son parent arabe mûsîqa. Ce dernier suppose l'utilisation d'instruments de musique, d'où une connotation négative si l'on associe la présence de ces derniers aux aspects prohibés du divertissement profane (entre autres, la danse et l'alcool), alors que l'essentiel de la «musique » soufie se réduit au chant (ghinâ'), et en particulier à la poésie mystique ou dévotionnelle; pareille « musique " n'est pas de la mûsîqa. Même le mot ghinâ' est chargé de connotations profanes, de sorte qu'on définit la musique soufie, ainsi que les autres formes de chant islamique (ibtihâlât, tawâshih et qisas dîniyya), comme de l'inshâd (chant prenant la forme d'un hymne) et l'interprète des chants religieux comme un munshid. Alors que l'essentiel de l'inshâd égyptien consiste en solos ou en chœurs, des instruments comme le duff (tambour sur cadre), le riqq (tambourin), la tabla (tambour en forme de gobelet), la kawala (flûte de roseau), la kamanga (violon), le 'ud (luth arabe) et même l'urg (synthétiseur) se retrouvent généralement dans certains types de chant religieux exécutés en dehors de la mosquée, particulièrement à l'occasion des mouleds.

Dans les exercices mystiques musulmans, centrés sur la proximité spirituelle avec Dieu, Son Prophète et d'autres figures saintes et sur la négation des désirs sensuels, l'esthétique ne doit pas constituer une fin en soi, mais plutôt un moyen permettant de développer le sentiment mystique. Le danger de confusion des moyens sensitifs et du but spirituel est à l'origine de la controverse qui, tout au long de l'histoire islamique jusqu'à maintenant, a entouré la question de la musique dans le rituel soufi. Même dans le soufisme égyptien d'aujourd'hui, des distinctions sont soigneusement opérées entre les pratiques musicales «spirituellement acceptables » et celles qui auraient une fin 
sensuelle en elles-mêmes. Le fait qu'on évite l'emploi du mot arabe mûsîqa et qu'on préfère celui d'inshâd à celui de ghinâ' en constitue un exemple. Un autre est l'emphase mise sur la fonction didactique de la poésie soufie, la musique n'étant alors considérée que comme un moyen de guider les croyants vers les bienfaits spirituels transmis par les textes, alors même que la poésie mystique dépasse souvent l'entendement de nombreux auditeurs.

L'inshâd soufi utilise une série de formes poétiques telles que qasîda, muwashshah, mukhammîs et murabba' (en arabe classique) et mawwal, sharh et zagal (en arabe dialectal). Les thèmes majeurs de cette poésie sont l'amour divin (al-hubb al-ilâhi), la louange et la glorification de Dieu (tawhîd), la supplication de Dieu (ibtihâlât), les requêtes en intercession (tawassul), la louange (madh) et l'amour (ghazal) du Prophète Muhammad, des ahl al-bayt et des awliyâ ${ }^{\prime}{ }^{15}$.

37 L'inshâd est fréquemment utilisé dans les confréries comme accompagnement d'un dhikr collectif (bien que certaines, comme la Tijâniyya, ne fassent pas usage d' inshâd dans le dhikr), ou à d'autres occasions au cours de la réunion. Dans le dhikr, l'importance de l'accompagnement musical varie d'une confrérie à l'autre, mais il se limite généralement aux percussions (tambours et battements de mains). Les chants servent partiellement d'instrument pédagogique destiné aux murîdin de la confrérie. La poésie utilisée par les confréries est souvent écrite (ou au moins choisie) par le shaykh fondateur pour exprimer et promouvoir sa mystique et ses enseignements philosophiques. Le shaykh qui préside le rassemblement - ou son représentant contrôle strictement la prestation des munshidîn, lesquels sont des amateurs venus des rangs de la confrérie ${ }^{16}$. Les meneurs chantent un verset et les autres répondent par un refrain, à moins qu'ils ne soient pris par un dhikr; il n'y a pas d'« audience $»^{17}$. Aussi la structure d'une telle musique est-elle nécessairement simple; la plupart des chants sont métriques, avec de courtes mélodies pré-composées. L'improvisation, la modulation et l'amétricité ne sont utilisées que pour des morceaux de solo occasionnels. L'influence de la musique arabe, classique ou populaire, est limitée, bien que le cadre des maqâmât (dans le cas présent, les modes mélodiques arabes) soit généralement utilisé.

En dehors des confréries, dans le monde du soufisme informel, l'inshâd consiste généralement en une performance en solo de munshidin professionnels accompagnés par un takht (petit ensemble hétérogène composé d'une percussion et d'un à trois instruments mélodiques; ce format est typique de la musique arabe urbaine et profane en Égypte jusque dans les années trente). Les mouleds sont le lieu spatio-temporel sacré de ces performances, près du sanctuaire du saint. Plus généralement, on loue les services du munshid pour différentes occasions socio-religieuses, comme un retour du pèlerinage à la Mecque, un mariage, une célébration des sept jours suivant la naissance d'un enfant, un anniversaire ou la formulation d'un vœu en échange de l'intercession et de la baraka d'un saint.

Ces événements, habituellement appelés layâli, ne sont généralement pas dirigés par un shaykh soufi car ils ne se situent pas dans le cadre des confréries. Le munshid contrôle lui-même tous les aspects de l'exécution, du choix de la poésie à la construction de la mélodie dans un style improvisé correspondant à ses goûts. Contrairement à l'inshâd des confréries le takht fait l'objet d'une forte amplification, ce qui crée une atmosphère de concert dans laquelle les musiciens se distinguent nettement des autres participants : ils disposent d'un micro et sont installés sur une sorte d'estrade. Les 
musiciens interviennent quand il faut recourir à un choeur de répondants, mais l'audience ne participe pas formellement à l'exécution de la musique, bien que les personnes qui la composent puissent s'adonner au dhikr, frapper dans leurs mains ou s'exprimer par des exclamations ; elles aussi sont largement dégagées de toute autorité (quoiqu'il y ait toujours au moins un mustaftah qui coordonne les mouvements du dhikr avec la musique). Aussi l'expression émotionnelle atteint-elle généralement un niveau nettement plus élevé que dans les confréries. La structure musicale y est également plus élaborée, car les exécutants sont des professionnels et elle implique un degré important d'improvisation et de spontanéité ainsi que l'utilisation de mélodies et de techniques inspirées de styles musicaux urbain et rural. L'essentiel de la performance tend à faciliter le dhikr et utilise pour ce faire une ligne métrique, bien que des segments totalement non-métriques soient également utilisés.

Dans la région du Delta, l'inshâd soufi professionnel utilise essentiellement l'arabe dialectal égyptien en recourant très largement au mawwâl (poème dialectal non mesuré, aux rimes variées), au sharh (semblable au mawwâl, mais avec une rime uniforme, comme une qasîda) et à la taqtûqa (simple chant dialectal strophique utilisé aussi bien dans sa forme poétique que musicale), tout en restant fidèle à la mesure du dhikr. Ces poèmes n'existent généralement que dans la tradition orale et on en connaît rarement les auteurs (bien que des poètes modernes, faisant du manwâl et du sharh, écrivent également pour des munshidîn). L'accompagnement musical est de style populaire, à ceci près que le tempo et le mètre sont limités pour s'adapter au dhikr, et évoque un ethos de type dansé.

41 De manière contrastée, en Haute Égypte et en particulier dans la province d'Assiout, de nombreux munshidîn professionnels interprètent des poèmes en arabe classique, $\mathrm{y}$ compris ceux, difficiles, de maîtres classiques comme 'Umar Ibn al-Farîd, Rabî'a al-'Adawiyya, al-Hallâj, Ibn 'Arabi, 'Abd al-Karîm al-Jîli, 'Abd al-Rahîm al-Bur'ai, alBusayri et autres. Le style vocal est libre, mais il ne recourt pas aux formes mélodiques typiques du mawwàl profane et il n'en appelle pas à une musique dansante comme dans le cas du chant dans le Delta. Le style sa'îdi (c'esl-à-dire de Haute-Égypte) est généralement considéré comme plus sérieux et difficile que l'inshâd du Delta.

Un exemple de grand munshid : Shaykh Yasîn al-Tuhâmi

Originaire du village de Hawatka près d'Assiout, Shaykh Yasîn al-Tuhâmi ${ }^{18}$ est aujourd'hui la figure de proue de la tradition sa'îdi, une tradition qu'il a contribué à définir au cours des vingt-cinq dernières années. Outre les imitateurs qu'il a suscités, sa notoriété en Égypte est telle qu'il a influencé le style de l'inshâd soufi jusque dans le Delta. À travers lui, l'on est amené indirectement à étudier une tendance musicale, sociale et religieuse répandue dans toute l'Égypte et dont il est le premier représentant,

43 Shaykh Yasîn est unanimement reconnu comme le plus grand munshid professionnel d'aujourd'hui en Égypte et est certainement le plus renommé. Les amateurs n'hésitent pas à parcourir plusieurs centaines de kilomètres pour avoir le privilège de l'entendre et, comme toute "vedette", son agenda est bloqué plusieurs mois à l'avance. Les séances se tiennent généralement sous le suwân (vaste tente multicolore utilisée traditionnellement en Égypte pour diverses occasions festives, officielles ou solennelles) et aux abords. Sur une estrade de bois recouverte d'un tapis, les musiciens se tiennent en demi-cercle autour du munshid. Le dhikr se déroulera face à cette estrade.

Si, en général, l'organisateur paye Shaykh Yasîn et loue l'équipement, la manifestation est ouverte gratuitement au public, Shaykh Yasîn donne parfois des représentations 
sans être rétribué, à l'occasion d'importants mouleds comme celui de Sayyidna-lHusayn et Sayyida Zaynab (le petit-fils et la petite-fille du Prophète, saints patrons du Caire) ou Sayyid Ahmad al-Badawi (célèbre saint de Tanta, dont le mouled est réputé attirer plus de deux millions de participants). Nombre d'amateurs enregistrent la prestation, qui sera par la suite largement reproduite et réécoutée à domicile ou dans des échoppes, voire commercialisée.

Shaykh Yasîn attire essentiellement des villageois et des migrants urbains récents, et aussi un nombre modeste, mais significatif, de nouveaux riches et d'intellectuels qui partagent une vision soufie de l'univers, même s'ils ne sont pas membres de confréries. Le public vient pour l'essentiel des environs, mais un grand nombre d'amateurs suivent ses représentations à travers l'Égypte.

La popularisation - certains disent l'introduction - d'instruments de musique profane comme la kamanga et le 'ûd dans l'inshâd soufi (instruments qui, contrairement à la flûte appelée nay ou kawala, n'y ont généralement pas leur place), de même que des percussions (généralement deux riqq et une tabla), constitue une des innovations de Shaykh Yasîn, si bien que son groupe finit par ressembler au takht prévaut dans la musique arabe profane. Vêtu comme un imam, il contrôle le déroulement des événements, combinant les fonctions de munshid et de shaykh dans les confréries.

La plupart des layâli de Yasîn sont divisées en trois parties ou wasla ${ }^{19}$ : la première comporte une base métrique de percussion et dure environ une heure et demie ; après une interruption de quelque vingt minutes, la deuxième partie, qui ne comporte ni percussion ni mètre, dure environ une demi-heure; elle peut être suivie d'une seconde pause ou, immédiatement, d'une troisième partie qui ressemble à la première mais de moindre durée. L'ensemble dure de deux heures et demie à quatre heures. L'inshâd à proprement parler est parfois précédé de récitations du Coran en solo (sourate introductive, ayât al-kursi puis courtes sourates) dans le style clair et simple du tartîl, après quoi il récite le hizb (prière soufie) d'une ou plusieurs, confréries (en particulier celles des organisateurs de la cérémonie). Ces rituels font office de bénédiction.

Après une pause, les instrumentistes s'accordent et évoluent imperceptiblement vers un prélude non métrique lors duquel est fixé le premier mode musical (maqam) avec une courte improvisation (taqsîm). Le coordinateur du dhikr (mustaftah) invile alors à se disposer en rangées se faisant face, perpendiculairement à l'estrade, les hommes désirant participer au dhirkr ${ }^{20}$. Shaykh Yasîn commence le dhikr en scandant le nom de Dieu. Le mustaftah reprend le rythme et entame, en frappant dans ses mains, un balancement qui sera repris par les participants. Donnant la réplique à Yasîn, les percussionnistes se lancent alors, entamant ainsi la première partie par un thème d'ouverture commun (Va a'zam af-mursafin) qui est une louange du Prophète. Il entonne ensuite un premier morceau dans lequel le mot madad (aide, assistance) est répété de multiples fois, suivi de différents noms. Il s'agît d'une supplique visant à obtenir l'assistance des personnages cités (par exemple, madad ya Sayyida Zaynab). Les requêtes habituelles sont généralement adressées à Dieu, au Prophète, aux saints, aux descendants du Prophète et aux grands poètes soufis, bien qu'en théorie n'importe qui puisse être cité. Les personnes citées sont fonction du lieu où se produit Shaykh Yasîn, et il est fréquent que les gens lui fassent parvenir des papiers sur lesquels ils ont écrit les noms de saints locaux qu'ils souhaitent entendre citer. La mention de saints dont le sanctuaire est à proximité - en particulier ceux en l'honneur desquels le mouled est célébré - suscite toujours une grande émotion dans la foule. Dans les prestations de 
Yasîn, le madad permet aussi de se dispenser des difficultés de la poésie et il est exécuté sur les tempos les plus rapides.

Après le madad d'ouverture, vient une séquence qui mêle morceaux de poésie et interludes musicaux. L'interlude, qui permet au chanteur de faire une pause et de consolider les changements du maqâm, est fait d'improvisations mélodiques ou de mélodies souvent reprises de chansons d'Umm Kulthum ou d'autres chanteurs arabes renommés. La poésie de Shaykh Yasîn puise à de nombreuses sources, mais chaque layla comporte généralement une ou deux qasîda principales dans lesquelles s'insèrent de courts extraits d'autres poèmes. Cette poésie, dans un langage mystique à la symbolique dense et à la langue pure, est souvent difficile à saisir et peu de gens en sont capables, alors que tout le monde comprend les extraits. Il n'empêche que se dégage du public l'impression qu'il ressent cette poésie et y répond par gestes, mouvements et exclamations, surtout à la clôture de phrases musicale-poétiques. Shaykh Yasîn choisit librement les poèmes correspondant à son état émotionnel et à l'humeur de ses auditeurs et il excelle dans le recours à des thèmes qui porteront l'émotion à son paroxysme. Le tempo augmente, te rythme du mètre va croissant pour culminer en madad $^{21}$.

50 Les participants au dhikr doivent suivre ces changements et sont guidés en cela par le mustaftah, qui établit les figures sans qu'il y ait contrainte. Leurs réactions émotionnelles sont nettement plus prononcées que dans les confréries dans la mesure où il n'y a pas d'autorité pour imposer de retenue, II n'est pas exceptionnel d'observer des comportements de transe qui ne seraient pas autorisés au sein des confréries. Le participant au dhikr peut sauter frénétiquement, se frapper, avec violence ou tomber inconscient à terre, interrompant parfois le cours de la cérémonie. Le comportement émotionnel correspond généralement au tempo de la musique et à la transparence du texte. Dans la mesure où les participants sont mobilisés par le dhikr, il leur est difficile de se concentrer sur la poésie. Quand Shaykh Yasîn atteint le point culminant et commence à chanter des madad, une émotion forte naît de la mention, facilement perçue, des noms du saint et du tempo rapide. Une personne en transe est habituellement décrite comme captive (fi hâ!), en extase (fi hâlat wajd), possédée (fi hâlât gazb) follement éprise (hayman), perdue (tâyih) ou ivre (sakrân). Comme nous le verrons plus loin, les mêmes adjectifs peuvent être appliqués au munshid.

51 La première partie s'achève et une pause intervient, au cours de laquelle l'estrade est assiégée par les gens désireux de saluer le Shaykh Yasîn. Certains considèrent en effet qu'il détient la baraka, dès lors qu'il est un munshid inspiré dont le père était un wâli. Les auditeurs ont envers lui le respect des disciples vis-à-vis de leur shaykh. Ceux qui le suivent d'une prestation à l'autre peuvent être considérés comme une espèce de confrérie virtuelle, constituée par et dans la prestation, dont il est le shaykh et le professeur.

La seconde partie est caractérisée par l'absence de mètre musical et de percussion. Shaykh Yasîn est uniquement accompagné d'instruments mélodiques. Il n'y a pas de dhikr, l'assistance reste assise et se concentre sur le chant. L'émotion, ici, est plus étroitement liée à la poésie qu'à la musique. Quand le shaykh achève une phrase, des exclamations d'appréciation s'élèvent de l'auditoire comme une délivrance émotionnelle. Plus la phrase poétique est longue, plus la réponse émotionnelle est forte, bien que fort peu de personnes puissent véritablement en saisir le sens. C'est ici 
que l'énigme de cette musique apparaît le plus clairement: comment la poésie ésotérique soufie peut-elle avoir un tel impact?

Une autre pause suit cette partie, à moins que le shaykh ne signale à ses percussionnistes qu'il souhaite entamer directement la troisième étape. La cérémonie se termine par une phrase de clôture conventionnelle (Salla Allah 'alayhi wa sallam : que Dieu le bénisse et lui donne la paix !) Les percussions s'arrêtent, Shaykh Yasîn apelle à la récitation de la fâtiha. Sa prestation est terminée.

Poésie, soufisme et émotion

La poésie de l'inshâd soufi est la principale explication de sa puissance. C'est le critère essentiel d'évaluation esthétique du munshid, de même que la caractéristique première de sa performance. Tout au long de la prestation, les auditeurs se montrent plus particulièrement touchés par certaines phrases et en mémorisent les termes pour les transmettre à d'autres, même s'ils ne peuvent en expliquer te sens. Quelle est l'origine de cette puissance poétique? Pourquoi la poésie soufie est-elle dotée d'une force affective largement supérieure à celle de son équivalent profane? La réponse est étroitement liée à la nature du système soufi.

La poésie soufie est qualitativement différente de la poésie profane, au même titre que le poète soufi est qualitativement différent de son homologue profane. Il est avant tout un soufi et sa poésie est l'expression de son expérience mystique, non celle d'un travail littéraire au sens habituel ${ }^{22}$. Elle résulte d'une nécessité interne, d'un appel s'imposant à lui, sorte de pression intérieure demandant à s'épancher.

56 Le statut spirituel du poète $a$, dans le soufisme, une incidence particulière sur l'impact affectif de ses paroles, non seulement dans la mesure où il a besoin d'inspiration spirituelle pour écrire, mais surtout dans le contexte de sa réputation spirituelle, qui lui garantit à la fois légitimité et puissance. Ecrire de la véritable poésie soufie requiert foi (imân), pureté (safa') et proximité avec Dieu (qurb min Allah).

Le poète soufi est socialement et mystiquement attaché à la généalogie soufie et au flux de baraka qu'il canalise. Il a des professeurs spirituels et il reçoit généralement le 'ahd (serment) d'un shaykh (depuis la naissance des confréries, du moins). Il a hérité de ces derniers la richesse de la spiritualité soufie dans laquelle il s'est immergé. C'est l'existence de ces significations appartenant au monde commun des soufis qui garantit l'authenticité du poète et de sa poésie. Le mysticisme et les enseignements du shaykh du poète soufi se reflètent dans ses propres écrits, au point que leurs voix se mêlent. Un adepte a ainsi affirmé que les poètes soufis, comme tous les saints, étaient spirituellement rattachés à 'Ali Ibn Abi Tâlib et, par lui, au Prophète. Le poète soufi peut également avoir ses propres disciples, auxquels il transmet son inspiration spirituelle sous une forme poétique, de même qu'il peut avoir été shaykh d'une confrérie pour laquelle il a composé, au profil de ses muridîn ${ }^{23}$, des poèmes exprimant son propre sentiment mystique. Le poète soufi, parce qu'il est inséré dans les grandes généalogies spirituelles du soufisme et qu'il transporte dans ses poèmes le vrai sentiment mystique (chose plus difficile pour celui qui écrit en prose), est le point de jonction de la tradition soufie et du vaste univers spirituel du soufisme, de même que la voie à travers laquelle le sens peut cheminer, de sa source dans l'Absolu à la prestation du poète.

La distinction entre le saint et le poète semble difficile à opérer. Un grand poète soufi est considéré comme un wâli, même s'il n'a pas fondé de confrérie. Ses paroles, texte quasi-sacré, garantissent le caractère sublime de ses réalisations spirituelles. Au Caire, 
'Umar Ibn al-Fârid a été vénéré comme un saint dès après sa mort et on lui attribue des

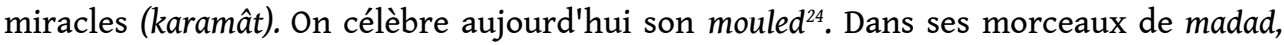
Shaykh Yasîn, au moment de citer les noms de saints, égrène souvent les noms de grands poètes soufis comme Ibn al-Fârid, Ibn 'Arabi, Rabî'a al-Adawiyya et al-Hallâj, parallèlement aux saints et aux ahl al-bayt. Le statut sanctifié des poètes soufis signifie que leur œuvre est considérée comme qualitativement différente de celle des poètes ordinaires; elle est emplie de ma'rîfa, cette gnose qui surgit au travers de l'illumination mystique, et authentifiée par la baraka, qui garantit l'autorité de l'ascendance spirituelle de l'auteur. Il n'y a rien de comparable pour le poète profane.

Le wali est également un poète. On attribue des poèmes à tous les saints d'Égypte comme Sayyid Ahmad al-Badawi et Ibrâhîm al-Disûqi, de même qu'aux ahl al-bayt. Ces saints ont tantôt composé eux-mêmes, tantôt inspiré un descendant spirituel. Des soufis reçoivent des poèmes de leur shaykh durant leur sommeil ; ils les lui attribuent alors, considérant cette transmission comme un moment où ils ont partagé un même sentiment. Cette collaboration créatrice entre un shaykh et son disciple assure la gloire au premier et l'autorité au second ${ }^{25}$. La production poétique attribuée à un shaykh comprend donc, en ce sens, bien plus que ce qu'il a écrit de sa propre main. Ahmad alRifâ'i (fondateur de la confrérie al-Rifâ'iyya), qui n'a jamais écrit aucune œuvre poétique directement, a ainsi inspiré des disciples (comme, au XIX ${ }^{\mathrm{e}}$ siècle, Abû-l-Huda al-Sayyâdi) qui ont écrit en son nom. La stature de l'auteur auquel la poésie est attribuée donne à ses paroles putatives une charge affective énorme.

En dépit de l'intériorité et de l'ineffabilité essentielles de l'expérience mystique, les significations et les formes de la poésie soufie sont universelles, reflétant en amont et en aval les chaînes de transmission soufies. Dans la mesure où le sentiment soufi est partagé au travers d'une tradition et d'un entraînement communs, dont la continuité est assurée par la relation de maître à disciple, les mots et les images utilisés pour exprimer ce sentiment sont empruntés à l'héritage soufi. Le poète soufi n'est parfaitement original ni par son expérience ni par sa langue; il s'inspire des différents courants d'une tradition qui émane de ses ascendants spirituels - comme nous l'avons $\mathrm{vu}$, ses paroles peuvent même être attribuées à l'un d'entre eux -, et se rattache au Prophète, lui-même inspiré par Dieu, source de toute signification.

61 La langue et les sentiments du poète ne sont pas exclusivement les siens, puisqu'ils sont partagés et réaffirmés par ceux qui le suivent selon une ligne menant directement au shaykh et aux murîlin vivants de la confrérie, ou au munshid et aux auditeurs d'une prestation d'inshâd soufi. De manière significative, on trouve des recueils de poésie soufie attribués à "l'un des hommes de savoir» (li ahad al-afâdif) ou à "certains muhibbîn » [li ba'd al-muhibbîn]. ${ }^{26}$

La généalogie spirituelle du poète et la paternité commune, inspirée et anonyme contribuent à établir un langage doté d'une force collective n'existant pas au même degré dans la poésie profane, parce qu'il s'agit de la force d'une expérience métaphysique partagée. La poésie soufie, parce qu'elle parle d'ultime réalité, est universelle et parle à travers les méandres du temps. Shaykh Yasîn affirme que la poésie des saints ne ressemble à aucune autre car elle est toujours neuve [bikr), révélant de nouvelles significations à chaque lecture. Cette propriété résulte pour partie du poids de la tradition partagée, qu'elle exprime de manière condensée (« chaque mot est un univers de sens", a dit un poète soufi), bien que ces significations ne soient accessibles qu'à ceux qui ont vécu une telle expérience. En un sens, le poète est le 
porte-parole incarné de toute une tradition, traduisant en langage ce que d'autres ne font que ressentir. C'est, pour ceux qui partagent la vision du monde soufie, un des secrets de cette puissance du verbe.

Il reste que le poète n'est pas seulement le "scribe » de l'expérience et de la tradition partagées. Il écrit pour exprimer une véritable expérience mystique, traduisant dans des mots ses sentiments profonds - peine, joie, amour ou désir. La poésie soufie majeure, celle qui traduit l'expérience du mystique ayant atteint un stade avancé, est l'expression spontanée du hâl, un état de transe non cognitif par lequel on est plongé dans la conscience des Réalités divines, et dont on émerge par l'émotion résultant d'une prise de conscience. Être en hâl nécessite l'absence de l'intellect en même temps, éventuellement, que la présence d'émotions qui se traduisent par tout un vocabulaire " amoureux "; hayman, walhan (fou d'amour), fi hâlat wajd (en extase), sakrân (ivre), mushtaq (qui se languit), hazîn (affligé) ${ }^{27}$. La force émotionnelle du hâl du poète imprègne mystérieusement ses paroles comme une qualité non objective, susceptible d'avoir une puissance hors du commun pour le soufi saisi par l'inspiration et la sensibilité (shafafiyya) spirituelles. Pour le non-soufi, le langage cryptique et émotionnel qui exprime l'expérience mystique, et notamment les shathiyât, expressions extatiques de l'union avec Dieu ${ }^{28}$, semblent pour le moins inintelligibles, sinon hérétiques.

De nombreux soufis prétendent que les poètes soufis ne sont pas des " poètes » (shu'arâ) au sens littéraire du terme, car la .poésie soufie procède de l'inspiration (ilhâm] en tant que traduction verbale de l'extase, et non d'un art (sinâ'a) requérant l'intervention de $l^{\prime}$ intellect ${ }^{29}$. Là où le poète profane est tenu de s'en remettre à une certaine technique, le poète soufi, avant tout mystique, ne peut séparer ses sentiments et son inspiration. Le sinâ'a est dénigré dans le soufisme ; les grands poètes soufis ont composé de manière spontanée, sans l'intervention de l'ego ni de l'intellect. Si l'art est l'oeuvre de ce dernier, considéré comme un voile jeté sur la vérité, l'expression authentique vient du cœur et de l'âme, lesquels procèdent du divin.

Le poète soufi a donc besoin, pour écrire, d'éprouver la douleur de l'amour-passion, puisqu'il est «amoureux de l'amour » ('âshiq biyi'shiq al-hubb). Le poète soufi traduit dans ses écrits la valeur soufie essentielle qu'est la sincérité (sidq]: il ne peut écrire que ce qu'il ressent, et c'est cette qualité qui confère à sa poésie toute sa puissance. Un proverbe fréquemment cité par les soufis dit que « ce qui vient du cœur atteint le cœur, ce qui vient de la langue n'atteint que l'oreille ». Comme nous le verrons plus loin, la même maxime vaut pour le munshid.

Décrivant les grands poètes soufis, Shaykh Yasîn préfère les désigner par l'expression : "celui qui s'adresse aux âmes par les âmes " plutôt que par le terme de shâ'ir, puisque leurs paroles procèdent de la langue de leur hâl, résultent de leurs sentiments et traduisent leurs émotions en langage. Un autre soufi explique que les grands poètes soufis, au moment d'écrire, sont " absents d'eux-mêmes " et comme "dissous" (madhûb), annihilés dans le divin (fanâ' ma'a Allah) ${ }^{30}$.

67 La poésie soufie, composée dans le langage de la poésie amoureuse profane, jaillit d'intenses sentiments d'amour pour Dieu, Son Prophète, les ahl at-bayt et les awliyấ'. Comme me l'a déclaré un poète soufi, quand un amoureux est avec son aimé, la poésie est superflue. Elle naît du désir (shawq) de l'aimé, qui conduit l'amoureux à ressentir de la souffrance (kadar). L'aimé n'existant ici que dans le royaume du spirituel ('âlam alarwâh), ce désir ne peut être satisfait par l'union physique. 


\section{lui-même. Toujours selon shaykh Yasin, les significations de la poésie soufie sont} innombrables parce qu'elle est écrite en état d'extase. Le produit en est infiniment riche et concentré. De plus, ces poèmes s'adressent individuellement à tout un chacun, à travers le temps et l'espace.

72 Si une telle poésie est appréciée par le soufi, ce ne peut donc être pour sa perfection littéraire, mais parce qu'elle exprime spontanément le sentiment spirituel (hâl) dont elle procède. La perfection du mètre (wazn) et de la rime (qafiyya) n'en est pas la priorité première, même si certains poètes soufis suivent impeccablement les règles de la prosodie. D'autres, en revanche, composent d'une manière techniquement imparfaite. Ce qui leur importe, c'est de communiquer leur expérience au récepteur ${ }^{33}$. L'ignorance des règles formelles de la poésie est considérée comme la pierre de touche de l'inspiration (ilhâm) véritable, la compétence intellectuelle explicite pouvant conduire facilement à l'artifice ${ }^{34}$. Comme nous le verrons, l'évaluation de la force expressive du langage spirituel, qui s'opère, dans la poésie soufie, au détriment de l'œuvre, correspond précisément à la valeur donnée à l'expression émotionnelle dans la prestation du munshid, même si c'est au prix d'une perte de raffinement vocal. Dans le cas de la poésie et du chant profanes, la situation est parfaitement inversée.

Les relations du munshid avec le poète et l'auditeur 
73 Le statut de wâli que détient le poète soufi et la position qu'il occupe dans les généalogies spirituelles du mysticisme islamique confèrent de l'autorité à ses paroles, son expérience mystique les sature de sens. Il reste au munshid ${ }^{35}$ à prêter une voix au poète en rendant ce sens palpable dans la prestation. Ces deux artistes de la création mystique peuvent être structurellement mis en parallèle. Le poète soufi, en tant que mystique et compositeur, est le médiateur de la réalité soufie (al-haqîqa) et de la poésie, enjambant ce fossé prodigieux qui sépare le sentiment mystique du langage. Le munshid, en tant que mystique et chanteur, est le médiateur du langage et de l'expression sonore affective, donnant à l'expérience mystique du poète une voix l'amenant impérieusement à créer du tarab lors de sa prestation. Seul le poète encode son sentiment en écrivant et il l'adresse à un lecteur qu'il ne peut voir. Le munshid, quand il interprète musicalement ce code en fonction de ses propres croyances et sentiments, produit instantanément une extase spirituelle et collective dans son face à face avec les auditeurs. Ce faisant, il crée du tarab même pour ceux qui ne comprennent pas les paroles du poète.

Comme nous l'avons montré, le tarab consiste essentiellement en des relations d'harmonie et d'échange de sentiments entre les participants, visant à atteindre l'unité des sentiments ou la fusion des identités individuelles. Comment le munshid est-il à même d'y parvenir, et mieux que le chanteur profane? C'est ce que nous allons examiner maintenant.

Le munshid soufi grandit dans un monde où les pensées, sentiments et actes soufis sont omniprésents. À l'occasion des mouleds et, plus tard, comme membre de confréries, il apprend à ressentir de l'amour pour Dieu, le Prophète, les ahl al-bayt, les awliyâ' et les shaykh. Il atteint un niveau mystique auquel il expérimente l'exultation de l'extase et la douleur du désir. Il s'initie aux « lumières du soufisme » - saints, shaykh et poètes - et apprécie l'autorité de leurs écrits. Il apprend le répertoire poétique de plusieurs confréries et ne se consacre pas exclusivement à un seul shaykh. La diversité lui donne davantage de souplesse lors de ses prestations devant des audiences hétérogènes ${ }^{36}$.

Il n'y a pas d'entraînement formel permettant d'abstraire la musique de son contexte. Le munshid apprend son art en assistant aux mouleds et en suivant les munshidîn établis. Il mémorise ainsi la poésie soufie dans un contexte lui-même pétri de sentiment soufi. Le sens du texte qu'il apprend est renforcé par les significations que lui donne ce contexte. Son expérience lui confère également ce fond commun émotionnel qu'il partage avec les autres soufis. Il vit avec la poésie (mu'âysha ma'a al-kalima) jusqu'au moment où il en ressent la signification. Pour Shaykh Yasîn, le munshid qui ne vit pas un poème intérieurement ne peut ni l'apprendre ni le chanter. Après l'avoir « vécu », il le mémorise sans effort et le chante aisément. Il n'a pas besoin de le comprendre ni de pouvoir l'expliquer clairement. Il s'agit davantage de percevoir son poids de texte parasacré, de cristallisation du numineux, d'avoir l'intuition de l'éventail immense des significations auxquelles il fait allusion.

Le grand munshid a des talents particuliers - sensibilité (ihsâs), intuition (basîra), discernement spirituel (shafafiyya) - qui tiennent probablement à son éducation dans un environnement soufi ou, au contraire, constituent ce qui l'a mené au soufisme. Il peut ainsi percevoir l'état émotionnel des auditeurs et choisir le texte qui y répondra. Ces talents facilitent son rôle de médiateur entre le poète et l'auditeur. Les muhibbîn insistent sur le fait que les aptitudes spirituelles de shaykh Yasîn résultent de son éducation religieuse (familiale, scolaire...). Son père, de plus, était un wâli auquel sont 
attribués de nombreux miracles, et son mouled est devenu un grand festival annuel dans son village natal. Cette éducation religieuse soufie est supposée être à l'origine de sa sensibilité et, partant, de son succès dans l'inshâd, avant son talent musical et vocal.

Le munshid professionnel a toutefois les qualités d'un bon chanteur. C'est un improvisateur expérimenté, capable d'ajuster en temps réel les dimensions poétique et musicale de la performance pour maximiser son effet émotionnel. Mais il se distingue du chanteur profane en ce sens qu'il ressent véritablement ce qu'il chante, le fait avec une sincérité (sidq) émanant du plus profond de son être. Il est alors capable d'exprimer ce sentiment dans sa prestation de façon à atteindre le cœur de ses auditeurs. Là encore, le sidq, valeur soufie essentielle, est cultivé dans la confrérie, et le munshid est supposé l'incarner.

79 La sensibilité du munshid est directement liée à sa croyance. De plus, il se produit dans un contexte religieux qui renforce et conditionne son expressivité, pour une audience d'auditeurs soufis en quête d'authenticité.

80 L'esthétique de l'expression, dans l'inshâd non confrérique, est fort différente de celle de la musique arabe profane. Alors que dans cette dernière, l'accent est mis sur la performance vocale, et qu'un chanteur à la technique parfaite ne sera pas discrédité même si sa prestation manque de chaleur, l'inshâd traduit la situation inverse. Dans le contexte du dhikr, l'expression émotionnelle est de première importance et la technique vocale secondaire. De plus, puisqu'il n'y a pas de shaykh pour présider la séance, le munshid est libre de prendre des risques. Il n'a pas à craindre l'imperfection vocale : il ne sera pas critiqué pour cela. Bien pire pour lui serait une prestation dénuée d'expression ${ }^{37}$.

81 Les grands poètes soufis sont considérés comme des wâli. On s'adresse à eux sur le mode honorifique en employant le titre de sayyidi («mon maître »). De manière analogue, les chanteurs soufis professionnels sont considérés comme des shaykh et ce titre est accolé à leur nom. En islam, ce terme peut désigner le savant en sciences religieuses ('âlim), le récitateur de Coran (muqri), celui qui dirige la prière (imam), le prêcheur (khâtib) ou le meneur soufi. Le munshid est considéré comme ayant un ou plusieurs de ces statuts.

De par l'importance de son répertoire poético-religieux et de son savoir religieux en général, il peut être considéré comme un 'âlim, en particulier s'il a étudié à al-Azhar. Le plus souvent, il aura étudié l'art de la récitation coranique (tajwîd) et peut réciter publiquement le Coran; comme le fait Shaykh Yasîn.Son expérience soufie et sa connaissance de la poésie lui confèrent généralement un statut de leader. Bien qu'habituellement il ne prête pas serment ni ne constitue de confrérie, il n'en attire pas moins des disciples qui convergent de partout pour l'écouter lors des mouleds et des soirées. Quand il se produit, on le considère comme l'imâm de la réunion car, dans le monde du soufisme informel où il se donne en représentation, il n'y a pas de shaykh de confrérie dont il faille respecter l'autorité, et il exerce donc un contrôle sur le dhikr. Il se vêt d'ailleurs comme un imâm, turban sur la tête et chapelet en main. À travers ses textes, qui peuvent contenir des exhortations, et par l'exploitation improvisée et affective qu'il en fait devant une audience qui lui répond très largement, il fait penser à un khâtib. Dans les relations sociales, on s'adresse au munshid comme à un shaykh, avec déférence et respect. Ce statut lui donne toute légitimité pour interpréter la poésie soufie. Contrairement au chanteur populaire, il n'est pas seulement un artiste (fannân) mais aussi un expert des sujets qu'il aborde. Les auditeurs le respectent à la fois pour 
son savoir et pour ses sentiments spirituels. Ils croient en lui, donc en ses paroles et en le sentiment dont il les revêt.

Le respect n'est pas le seul élément de la relation du munshid et de l'auditeur. En tant que centre d'une confrérie virtuelle, le munshid est aussi une figure aimée qui entretient des relations personnelles avec nombre d'auditeurs et connaît maints d'entre eux par leur nom. Ces relations sont renforcées, sur le plan métaphysique, par la shafafiyya (perception spirituelle). On dit par exemple de Shaykh Yasîn qu'il a une relation forte avec certains auditeurs parce que leurs âmes étaient proches dans le 'âlam al-azali. Ces relations favorisent l'empathie entre celui qui se produit et les auditeurs et, partant, un libre flux d'émotion dans le dhikr, ce qui non seulement provoque l'émergence de tarab mais est également crucial pour les mécanismes de feedback et de contrôle de la prestation, comme nous allons rapidement le voir.

Le munshid occupe une position idéale pour établir une relation étroite avec le poète et son texte et faciliter le développement du tarab dans la prestation. Il saisit le sentiment mystique du poète par le biais du texte; il se trouve en symbiose avec les mots du poème et son état émotionnel rejoint celui du poète. Un poète soufi explique cette relation en ces termes : "Le munshid doit être parfaitement familiarisé avec l'approche poétique du poète qu'il chante. Il doit être confiant en l'authenticité de ce dernier ». S'il y parvient - et son expérience soufie l'y aidera -, il chantera en étant imprégné du tarab du poète.

Des relations personnelles entre le chanteur et le poète sont également possibles dans le contexte soufi. Nombre de chanteurs demandent à des poètes soufis de composer pour eux, comme cela existe dans la musique profane. Cependant, munshid et poète sont beaucoup plus proches que dans le cas d'une simple association professionnelle. Le poète peut enseigner au munshid ses poèmes, mais aussi en diriger l'interprétation et l'accompagner aux mouleds et soirées, où il lui manifestera ses encouragements.

Par ailleurs, le soufisme offre la possibilité de relations spirituelles intimes, franchissant le temps et l'espace, entre le munshid et le poète, puisque les âmes des saints soufis sont « libres ", après leur mort, de voyager où bon leur semble. En Égypte, on admet généralement que le sens de la poésie réside à l'intérieur du poète (bâtin alshâ'ir), ce qui le rend inaccessible. Le soufisme a donné naissance à une poésie des plus profondes et mystérieuses tout en permettant au sens d'être révélé à travers certaines formes d'intuition. On peut donc avoir accès au sens caché par le biais de connexions spirituelles directes, avec le poète ou par son intermédiaire. Ce peut être sous forme de rêves, de visions, voire de rencontres. Un shaykh soufi m'a ainsi confié être capable d'entrer en contact avec 'Umar Ibn al-Fârid. Le munshid peut également atteindre une relation spirituelle intime avec le poète dont il chante l'œuvre, au point que ses auditeurs ont le sentiment d'entendre la voix du poète lui-même.

Le poète, le munshid et le tarab dans la prestation de dhikr

Dans une prestation idéale, le munshid doit être le canal par lequel la voix du poète sera entendue dans le dhikr. Pour que cela se produise, il doit y avoir fusion des sentiments du poète, du munshid et de l'auditeur, véritable quintessence du tarab. Nous allons maintenant examiner comment cette unité est réalisée.

88 La fonction de l'inshâd soufi dans le dhikr est en partie d'intensifier l'atmosphère émotionnelle. Les initiatives prises par le munshid quant au texte, au rythme, à la tonalité, etc., lui permettent de créer l'émotion et de la façonner. En même temps, il 
doit adapter sa prestation à l'atmosphère en fonction du feedback que lui renvoient les auditeurs sous forme de gestes, de mouvements, de réponses audibles. Une telle adaptation est possible parce que l'inshâd soufi est improvisé, donc flexible. Le feedback émotionnel que le munshid reçoit des auditeurs favorise en outre l'échange de sentiments requis pour la production de tarab.

Ce cycle de feedback et d'adaptation fait également partie de la dynamique du tarab dans la musique profane. Pour des raisons commerciales cependant, l'improvisation fait place à des techniques musicales prédictibles et répétables. À cela s'ajoute le fait que l'esthétique musicale inspirée de la musique classique occidentale a contribué à favoriser la passivité de l'auditeur, la musique précomposée et la notation fixe ainsi que le déclin de l'autorité du chanteur au profit du compositeur, du chef d'orchestre et de l'adaptateur. Tous ces facteurs ont contribué à l'essoufflement du tarab dans la musique profane.

Par contrasté, dans la musique soufie, le tarab est resté relativement imperméable à cette commercialisation et à cette occidentalisation. Il ne suffit pas de relever les facteurs historiques qui tendent à préserver du changement les traditions religieuses : le changement est constant et la musique soufie a considérablement évolué, même depuis la fin des années soixante (avant lesquelles il y avait pénurie de matériau enregistré). Ce qu'il importe de relever, c'est que cette évolution ne s'est pas opérée au détriment du tarab. La raison en est que cette musique remplit, dans le dehors confrérie, une fonction religieuse particulière, la construction d'une émotion spirituelle, qui requiert les conditions d'une prestation Iive - flexibilité, improvisation, feedback et adaptabilité - et que ce sont ces conditions qui favorisent le tarab.

91 Le munshid n'est donc pas tenu, lors de ses prestations, de chanter tel type de poèmes plutôt que tel autre, pas plus qu'il ne doit commencer un poème par le début ou le poursuivre jusqu'à la fin. Il dispose au contraire d'une grande marge de manœuvre, improvisant par rapport à un texte qu'il construit au moment même de sa prestation, cela en réponse au feedback de ses auditeurs. Cela lui permet de s'adapter aux circonstances du moment.

Les prestations d'inshâd hors confrérie se déroulent dans une atmosphère particulièrement festive. Lors des mouleds, cela se passe généralement à proximité du sanctuaire du saint. Les paroles du poète sont à la fois renforcées et illustrées par le contexte. C'est ce dernier qui rend le chanteur sensible aux paroles du poète en le plongeant dans un état similaire à celui dans lequel le poème a été composé. Shaykh Yasîn affirme être particulièrement influencé par le contexte de la prestation - densité de la foule, présence de sanctuaires dispensant la baraka, motifs de l'événement... Un mouled exerce une influence plus importante, ajoute-t-il, du fait de la sacralité du temps et du lieu et de par la présence du wâli. L'état mental du munshid, quand il s'apprête à chanter, s'apparente à celui du poète quand il s'apprête à écrire.

Le munshid se produit en ayant en tête un répertoire poétique varié, ancien et nouveau. En exploitant ce répertoire, il construit spontanément un texte qui traduit son propre état émotionnel tout en tentant simultanément de détecter l'état émotionnel de ses auditeurs et de s'en rapprocher. Il s'efforce de ressentir aussi profondément que possible le sens du texte pour pouvoir chanter avec une authenticité accrue. L'état spirituel et émotionnel des participants se modifie en conséquence, et cette modification provoque à son tour des changements dans le feedback dont bénéficie le chanteur. En manipulant avec précaution le matériau dont il dispose, le munshid 
conduit la prestation de manière à élever au plus haut degré le sentiment de partage entre les participants.

Shaykh Yasîn affirme ne jamais préparer ni choisir ses poèmes avant de se produire. Ses paroles lui viennent naturellement de l'atmosphère du moment et lui sont « imposées » par ce qu'il ressent. Il peut ainsi répéter à l'infini certains vers, en omettre d'autres, etc. La fragmentation des poèmes soufis accentue encore la priorité de l'affect sur l'intellect. Au moment de la prestation, le but reste l'expression, la communication et l'unité émotionnelles. C'est à cette fin que le munshid extrait de son répertoire les éléments constitutifs (phrases, mots, voire simples phonèmes) qu'il utilise comme stimuli émotionnels. Il peut ne chanter qu'un vers, puis passer à un autre poème, répéter à l'infini le même vers ou le même mot. Il se concentre sur des images, des concepts et des sons au détriment de la logique et du flux narratifs. La compréhension du poème soufi, déjà difficile quand il est présenté dans son intégralité, dépend ici de facultés d'interprétation affectives. Comme le Shaykh Yasîn a pu le dire, il importe peu de ne pas comprendre les paroles; l'essence du dhikr se trouve dans la sensibilité, l'échange émotionnel.

De par l'habileté du munshid et la puissance du dhikr, les participants peuvent entrer dans un état de transe. Le Shaykh Yasîn connaît généralement cet état quand il se donne en représentation. Il n'y a pas, alors, de division « entre la langue et le cœur ». Sans cela, il ressemblerait à ses imitateurs les moins doués. Un autre poète soufi insiste sur le fait que le munshid, lors de sa prestation, doit être " absent à lui-même » (yaghîb 'an nafsu). Il explique comme suit le phénomène du hâl dans le dhikr: il y a absorption (indimâg) dans le dhikr et en Dieu. C'est quand on se perd, que l'on est absent à l'entourage, que l'on peut entrer en état de hâl. On est "préoccupé de Dieu », qui nous accorde un hâl selon Sa nature. Le hâl se produit quand, submergé par la beauté de la création, l'adepte « s'absente en Dieu ».

Le chant du munshid peut donc être triplement imprégné de hâl: celui du poète, qui a composé en état de hâl, celui du chanteur, qui retransmet ses paroles dans un état similaire, et celui de l'auditeur, que le chanteur essaie de conduire à ce même état. Si le munshid parvient à réunir ces trois éléments dans sa prestation, le niveau de tarab sera alors exceptionnellement élevé.

De par sa relation au munshid, le poète peut jouer un rôle actif dans l'inshâd soufi. C'est particulièrement manifeste dans le cas de poètes vivants, qui assistent au dhikr et encouragent le chanteur, comme nous l'avons vu plus haut. Shaykh Yasîn chante avec plus de puissance quand l'un de ses poètes et associés, Shaykh 'Abd al-'Alîm, se tient à ses côtés.

Dans l'univers spirituel soufi, le poète disparu peut également intervenir dans la prestation, le monde des âmes n'étant pas soumis aux lois physiques du monde visible. Le dhikr et la concentration des adeptes, les paroles, la répétition des noms de Dieu..., peuvent favoriser certaines présences spirituelles, dont celle du poète. Pour Shaykh Yasîn, chanter tel poète, c'est solliciter sa présence, certains affirment que le poète " enveloppe de son ombre » le munshid qui se produit. D'autres estiment que le poète l'inspire quant au sens profond de ses paroles, de sorte que son chant est plus influent. Shaykh Yasîn, qui se produit annuellement au mouled du grand poète 'Umar Ibn alFârid, utilise à cette occasion de nombreux extraits de son œuvre.

Conclusion 
L'on a tenté d'esquisser ici le rôle de la poésie dans la production de tarab lors des prestations d'inshâd du soufisme informel. Le poète soufi, à la fois écrivain et saint, demeure une référence constante du soufisme et ses poèmes s'imposent au lecteur ou à l'auditeur avec tout le poids de la tradition qui les précède. Le poète écrit à partir de son expérience mystique personnelle et ses poèmes, toujours éprouvés en .profondeur, sinon techniquement parfaits, communiquent avec force l'impact affectif de cette expérience à ceux qui en ont goûté de semblables.

Quant au munshid, $a$ fa fois chanteur et shaykh, il partage l'univers du poète et en vient par conséquent à partager son expérience, à incarner ses paroles. Sa sensibilité lui donne accès à une compréhension intuitive des poèmes et à une perception juste des besoins des auditeurs. Son statut de shaykh lui donne autorité et puissance lors de ses prestations. Ses talents musicaux lui permettent enfin d'exprimer musicalement l'essence affective de la poésie soufie. Médiateur idéal entre le poète et l'auditeur, inspiré par le premier et inspirant le second en sélectionnant les poèmes en fonction de son hâl et du feedback qu'il reçoit des auditeurs, il dispense sa prestation avec précaution, à la recherche de cette fréquence insaisissable où poète, munshid et auditeur sont en résonance, ce lieu de confluence où les frontières individuelles se dissolvent et ne laissent qu'une fusion émotionnelle, celle du tarab, quand l'auditeur peut entendre chanter la voix du poète.

\section{NOTES}

1. Ce travail repose sur deux années de recherche sur la musique et le soufisme en Égypte. Je remercie tous ceux qui, aux États-Unis (Jihad Racy, Timothy Rice, Hossein Ziad, Douglas Hollan, Robert Winter, Jacques Maquet) et en Égypte (Qadri Sourour), m'ont prodigué leurs conseils. Je transmets également toute ma reconnaissance à Shaykh 'Abd al-'Alim al-Nakhayli, Shaykh 'Izz al-Hawari, Shaykh Yasîn al-Tuhâmi, Taha Gad Salîm, Muhammad 'Umrân, Ibrâhîm 'Abd al-Hâfez, 'Abd al-Hamîd Huwwas, Valérie Hoffman, Virginia Danielson, Dwight Reynolds, Earle Waugh et à bien d'autres encore. La Fulbright Commission in Egypt, l'American Research Center in Egypt, l'Université de Californie, Los Angeles, et le Social Science Research Council ont aidé à la réalisation de cette recherche.

2. Sur te tarab et l'esthétique, les catégories et les différents genres musicaux, cf. Racy A. J. : « Music in Contemporary Cairo: A Comparative Overview », Asian music 13 (1), 1981, p. 4-26 ; « Musical Aesthetics in Present-Day Cairo », Ethnomusicology 26, 1982, p. 391-406 ; « The Wasiah: A Compound-Form Principle in Egyptian Music », Arab Studies Quarterly, 5 (4), 1983, p. 396-403.

3. Racy A. J., « Creativity and Ambience: An Ecstatic Feedback Model From Arab Music», World of Music, 33 (3), 1991,p. 7-28.

4. Le mot tarab a une connotation séculière et peut, dans un contexte religieux, être remplacé par des quasi-synonymes comme nashwa (extase). Le tarab peut aussi faire référence à un style spécifique de musique profane urbaine (notamment celle qui 
produit le tarab). Pris dans ce sens, la présence de tarab dans la musique soufie peut faire l'objet de critiques portant particulièrement sur l'intrusion dans le dhikr (répétition incantatoire du nom de Dieu, accompagnée de balancements du corps. N.D.L.R.), d'instruments musicaux ('âlat al-tarab) et de mélodies profanes. Toutefois, la plupart des soufis ne semblent pas faire d'objection à l'utilisation du mot tarab, dans un sens plus abstrait, pour décrire la musique soufie.

5. Je parie au masculin par facilité linguistique. J'aimerais toutefois faire une remarque sur la participation des femmes dans le soufisme égyptien, dans la mesure où cet article n'aborde pas directement la question. Les femmes sont présentes, dans le soufisme, en tant que saintes (surtout parmi les ahl al-bayt comme la petite fille du Prophète, Sayyida Zaynab), poétesses (comme la grande Rabî'a al-'Adawiyya ou la très contemporaine Égyptienne 'Alia al-Ja'r), munshidîn (comme Shaykha Sabah, qui chante à l'occasion de mouleds dans la région du Caire), shaykha de confréries soudes (comme Hagga Zakiyya, qui est enterrée à côté du sanctuaire de Sidi Abu-l-Hasan al-Shâdhîli), comme membres de turuq (muridîn), c'est-à-dire de confréries, ou encore comme participantes au système soufi informel de croyances et de pratiques. Il faut toutefois noter que les femmes restent minoritaires dans toutes ces catégories, à l'exception de la dernière. 6. Sur le soufisme égyptien contemporain, voir Hoffman-Ladd V., Sufism, Mystics and Saints in Modem Egypt, University of Soutn Carolina Press, Columbia S. C., à paraitre. Cet ouvrage constitue à ce jour l'étude la plus approfondie sur ce sujet.

7. Le concept de 'âlam al-arwah ou de 'âlam al-ghayb (monde caché) illustre l'idée soufie selon laquelle toute chose est constituée d'un aspect intérieur (bâtini], non visible par la perception ordinaire mais uniquement par ceux qui sont dotés de discernement spirituel (shafafiyya), talent spirituel inné qui peut également être développé par l'élévation de l'âme et le perfectionnement du soi grâce à l'entraînement soufi. L'acuité visuelle (basar), liée à l'esprit ('aql) et perceptrice de la réalité matérielle, se distingue donc de l'intuition (basîra), située dans l'« œil du cœur » ('ayn al-qalb) et perçoit la réalité spirituelle essentielle et permanente. Dans la mesure où l'expérience esthétique et l'émotion dépendent de la perception, cette extension mystique de la perception, qui va de l'œil de l'esprit à l'œil du cœur, implique une extension mystique de la sensibilité esthétique, de la communication et de l'affect. Repris dans ces termes, cet article pourrait être résumé dans les termes suivants : ce qui fonde la puissance émotionnelle de la musique soufie, c'est de se rattacher à un monde esthétique fondé sur la perception mystique, là où la musique profane se fonde uniquement sur la perception ordinaire.

8. Sur la question de l'amour et de la dévotion pour le Prophète et sa famille, cf. Valérie Hoffman-Ladd, « Devotion to the Prophet and His Family in Egyptian Sufism », International Journal of Middle East Studies 24 (4), p. 615-637.

9. Le wâli peut être enterré ou non à l'endroit même du maqâm. Les soufis affirment que chaque wâli a 40 maqâm.

10. De Jong F., « Cairene Ziyara Days: A Contribution to the Study of Saint Veneration in Islam », Die Welt des Islams 17 (1-4), 1976-1977, p. 26-43.

11. Les awliyâ' forment une hiérarchie spirituelle, le rang supérieur étant le qutb (pl. aqtâb), le pôle ou l'axe du monde. Pour plus d'informations, cf. A. Schimmel, Mystical Dimensions of Islam, University of North Carolina Press, Chapel Hill, 1975, et V. HoffmanLadd, Sufism, Mystics..., op. cit.

12. Pour une description, détaillée des mouleds d'Égypte depuis la moitié du $\mathrm{Xx}^{\mathrm{e}}$ siècle, cf. J. W. McPherson, The Moulids of Egypt, Nile Mission Press, Le Caire, 1941. 
13. À la seule exception du mouled du Prophète lui-même, qui est célébré dans tout le monde islamique le 12 Rabi' al-awwal du calendrier musulman.

14. Cf. Waugh Earl H., The Munshidin of Egypt: Their World and Their Song, University of South Carolina Press, Columbia, S.C-, 1989.

15. Je suis redevable à I. 'Abd al-Hâfiz de certains éléments de cette classification.

16. Pour un commentaire sur le rôle du munshid et de l'inshâd au sein de la confrérie et sur la relation entre te shaykh et le munshid, cf. Waugh, op, cit., p. 68.

17. J'entends ici par « audience » tous les participants autres que les chanteurs et les musiciens quand la distinction entre ceux qui font de la musique et les autres semble bien établie. C'est souvent le cas hors des confréries, mais rarement en leur sein.

18. Shaykh Yasîn est également présenté dans Waugh, op. cit.

19. Quand il se produit à l'occasion de mouleds, Shaykh Yasîn ne chante qu'une wasla, mais elle dure plus longtemps.

20. Les femmes, quand elles participent au dhikr, se tiennent au bord, rarement dans les rangées principales.

21. Voir Waugh, op. cit.. p. 123.

22. Cela n'est pas sans rappeler la remarque du grand poète soufi Mawlana Jalal at-Dîn Rûmi : « Mon Dieu, je me soucie peu de poésie, il n'y a même rien de pire à mes yeux. Mais je dois m'en acquitter, tout comme un homme plonge ses mains dans les tripes et les lave pour satisfaire l'appétit d'un hôte désireux d'en manger. » Cité par Schimmel

A., As Througn a Veil: Mystical Poetry in Islam, Columbia University Press, New York, 1982, p. 12.

23. Tel est le cas de deux shaykh-poètes modernes et prolifiques du Caire. Shaykh Salih al-Ja'far et Shaykh Muhammad Madi Abû-l-'Azâ'im.

24. Homerin T. E., From Arab Poet to Muslim Saint: Ibn al-Farid, His Verse, and His Shrine, University of South Carolina Press, Columbia, S. C.

25. Les techniques poétiques du takhmîs et du tashtîr constituent un autre mode de collaboration créatrice. Elles impliquent l'interpolation d'un nouveau matériau dans une qasîda existante, en en maintenant la rime et le mètre. De tels poèmes sont courants en soufisme (A. Schimmel, As Through a Veil, p. 46).

26. On pourrait considérer cette confusion sur la paternité de la poésie comme symptomatique de l'ignorance nourrissant l'émotion. De nombreux adeptes de Shaykh Yasîn, par exemple, croient qu'ils chantent essentiellement l'œuvre de 'Umar Ibn alFârid. La puissance de leur émotion semble dériver de cette croyance. Que se passeraitil, dès lors, s'ils venaient à perdre cette croyance ? La poésie en perdrait-elle sa puissance affective ? Pareilles interrogations reflètent une mécompréhension de la notion de création dans la tradition soufie. S'il est vrai que de nombreux poèmes attribués à Sidi 'Umar ne figurent pas dans le recueil de son œuvre poétique mais dans ceux de poètes mineurs, il n'en demeure pas moins que l'attribution des poèmes, en soufisme, tient étroitement à la croyance dans le réseau soufi en général, lieu de partage des significations et expressions et d'émergence de l'inspiration spirituelle, Ce type d'interrogations procède d'une conception de l'œuvre d'art comme création originale, produite par le génie d'un individu isolé, ce qui n'est pas le cas dans le soufisme. Un poète soufi écrivant après Sidi 'Umar ne peut que faire écho à ses pensées, et un poète écrivant avant lui entendra ses paroles résonner dans son recueil, parce que tous puisent à la même source.

27. Ces mots peuvent avoir différentes significations dans les traités soufis, mais ils sont utilisés dans la pratique comme des quasi-synonymes. 
28. Cf. Ernst C. W., Words of Ecstasy in Sufism, S. Univ. of New York Press, Albany,1985.

29. Sur l'ilhâm et son application à l'inshâd, voir Waugh, op. cit., p. 86.

30. La métaphore de la dissolution (dhawb) pour rendre compte de la fusion d'une âme avec une autre ou avec Dieu est une métaphore commune au langage soufi, et parfois utilisée pour décrire l'échange émotionnel du tarab.

31. Homerin, op. cit., p.39.

32. Le poète n'est pas le seul chez qui l'on trouve cet état émotionnel exigeant d'être exprimé. Tarab, wajd, hâl, toutes ces situations doivent pouvoir être relâchées, ce qui dépend des capacités de celui qui les vit. Le poète écrit, le munshid chante, certains dansent, d'autres peuvent tomber inconscients ou faire montre d'un comportement bizarre ou violent.

33. Schimmel commente un poème de Rabî'a al-'Adawiyya en affirmant que « le sentiment de l'auteur est plus fort que son art » (op. cit., p. 18).

34. L'illettrisme du Prophète Muhammad constitue, de manière analogique, la pierre de touche de l'authenticité de la révélation coranique.

35. II est ici question du munshid soufi professionnel qui se produit en dehors du cadre des confréries. Le munshid de confrérie chante une poésie semblable mais agit sous l'autorité d'un shaykh à l'intérieur d'une forme rituelle plus rigide, qui empêche généralement une émergence comparable de tarab. Par ailleurs, la confrérie est une structure sociale dynamique qui ne dépend pas exclusivement de la pratique du dhikr pour être dotée de cohésion identitaire et émotionnelle.

36. Waugh décrit cette diversité du répertoire comme une " exigence œcuménique » faite au munshid qui chante en dehors des confréries (op. cit., p. 74).

37. Le contraste de la situation respective du munshid et du chanteur profane de tarab traduit le contraste de la situation respective du poète ordinaire (avant tout préoccupé de composition littéraire) et du poète soufi (avant tout préoccupé d'exprimer une expérience intérieure). Pour le premier, la perfection technique l'emporte sur l'expression, tandis que c'est l'inverse pour le second.

INDEX

Mots-clés : islam, religion, soufisme, poésie, musique, mawlid, mystique

\section{AUTEUR}

MICHAEL FRISHKOPF

Université de Californie, Los Angeles 